D.O.I: $10.3895 / \mathrm{S} 1808-04482013000300004$

\title{
METODOLOGIA SERVQUAL: UMA FERRAMENTA PARA AVALIAÇÃO DA QUALIDADE DE SERVIÇOS EM UMA EMPRESA DE COMERCIALIZAÇÃO DE MÁQUINAS AGRÍCOLAS
}

\section{METHODOLOGY SERVQUAL: A TOOL FOR ASSESSING THE QUALITY OF SERVICES IN A COMPANY BUSINESS AGRICULTURAL MACHINES}

\author{
Andressa Pisoni ${ }^{1}$; Juliana Andreia Rüdell Boligon ${ }^{2}$; Flaviani Souto Bolzan Medeiros ${ }^{3}$; Élio Sérgio \\ Denardin $^{4}$; Lisandra Taschetto Murini ${ }^{5}$ \\ ${ }^{1}$ Centro Universitário Franciscano - UNIFRA - Santa Maria - Brasil \\ andressa.pisoni@ hotmail.com \\ ${ }^{2}$ Centro Universitário Franciscano - UNIFRA - Santa Maria - Brasil \\ julianaboligon@unifra.br \\ ${ }^{3}$ Universidade Federal de Santa Maria - UFSM - Santa Maria - Brasil \\ flaviani.13@gmail.com \\ ${ }^{4}$ Centro Universitário Franciscano - UNIFRA - Santa Maria - Brasil \\ eliodenardin@hotmail.com \\ ${ }^{5}$ Centro Universitário Franciscano - UNIFRA - Santa Maria - Brasil \\ lisandra@unifra.br
}

\begin{abstract}
Resumo
Em meio às constantes mudanças no ambiente empresarial, a concorrência acirrada, bem como o desenvolvimento de novas tecnologias, é importante para que as empresas consigam avaliar se os seus produtos elou serviços estão atendendo às expectativas do cliente. E através da aplicação da escala Servqual é possivel avaliar essas diferenças ou principais discrepâncias entre a expectativa que o cliente tinha em relação ao serviço com a sua percepção após o serviço oferecido. Nesse contexto, o presente estudo tem como objetivo realizar uma avaliação nos serviços prestados por uma empresa de comercialização de máquinas agrícolas, visando agregar valor aos seus processos $e$ operações de trabalho. Quanto aos procedimentos metodológicos, a pesquisa caracteriza-se como qualitativa e quantitativa, do tipo descritiva, sendo realizada utilizando a ferramenta Servqual através da aplicação de um questionário a uma amostra composta por 40 clientes da empresa em estudo. Os resultados revelam que na maioria das variáveis analisadas a expectativa dos clientes excedeu a percepção dos serviços prestados, o que reflete que a empresa precisa tomar algumas ações corretivas a fim de reduzir esses gaps encontrados e, a partir do conhecimento dessas diferenças, têm-se condições de aprimorar e trabalhar em cima das operações ou processos que necessitam ser melhorados.
\end{abstract}

Palavras-chave: qualidade; serviços; clientes.

\section{Introdução}

A qualidade é entendida normalmente como um atributo de produtos ou serviços, mas pode referir-se a tudo que é feito às pessoas (MOREIRA, 2008). Entretanto, Silva, Kovaleski e Gaia 
(2011, p. 143) lembram que "existem várias conceituações para o termo qualidade, este fato é que torna difícil manter uma posição definitiva para a ideia do que realmente seja a qualidade. O que se sabe ao certo é que a qualidade chegou para ficar, seja no trabalho, em casa, na produção de bens ou na prestação de serviços". E acrescentam, ainda, que em qualquer atividade humana a qualidade tornou-se imprescindível.

Por isso, conforme Martins e Laugeni (2005), os trabalhos em serviços estão se tornando cada vez mais específicos, necessitando de uma qualificação e capacitação superior dos funcionários. Segundo Las Casas (2006, p. 297), "toda a prestação de serviço poderá ser diferenciada através de um dos pés de serviços”. O profissional poderá diferenciar seus serviços com as pessoas, com os processos, com os procedimentos ou mesmo com o perfil da organização.

Para Zeithaml, Bitner e Gremler (2001), serviços são atos, processos e atuações oferecidos ou produzidos por uma entidade ou pessoa, para outra entidade ou pessoa. O serviço inclui todas as atividades econômicas cujo resultado não é um simples produto físico ou construção, mas o que é consumido no momento em que é gerado e oferece valor agregado em formas que constituem, em essência, os interesses daqueles que adquirem (como conveniência, diversão, geração em hora oportuna, conforto ou saúde).

De acordo com Fitzsimmons e Fitzsimmons (2010), qualidade em serviço é um tema complexo, como demonstra a necessidade de uma definição que aborda cinco diferentes dimensões: confiabilidade, responsabilidade, segurança, empatia e fatos concretos. Utilizando essas dimensões, o conceito de falha da qualidade em serviços é apresentado. O mesmo baseia-se na diferença entre a expectativa de um cliente com relação ao serviço e sua percepção de como ele é prestado. Dessa forma, uma maneira de avaliar os processos para que os mesmos possam ser melhorados é através da escala SERVQUAL. Trata-se de uma ferramenta de pesquisa que mede qualidade em serviços de determinada organização, visando à melhoria de seus processos produtivos para prestar ao cliente final um serviço que agregue valor.

Através da aplicação da escala SERVQUAL é possível avaliar os gaps, ou seja, as diferenças ou principais discrepâncias entre a expectativa que o cliente tinha em relação ao serviço de determinada empresa com a sua percepção após o serviço prestado. A partir do conhecimento dessas diferenças têm-se condições de aprimorar e trabalhar em cima das operações ou processos que necessitam ser melhorados.

Na visão de Veiga (2000), a quantidade de marcas e tipos de máquinas disponíveis no mercado e os custos indiretos associados à pontualidade das operações tornam a seleção desses sistemas uma atividade complexa. As empresas encontram-se inseridas em um ambiente instável, o qual faz as mesmas buscarem um diferencial competitivo. 
E apesar do conceito de competitividade organizacional não ser algo novo, através da inovação e do pensamento estratégico pode-se dizer que quase sempre se torna possível enxergar novas oportunidades para se obter vantagem competitiva, independentemente do ramo de atuação (CARVALHO; CAMPOS, 2012). Sendo assim, têm-se no mercado de máquinas agrícolas, opções de empresas que estão buscando esses diferenciais, adequando seus processos para otimizar lucros e atender de maneira mais satisfatória seus clientes.

Assim, o presente estudo tem como objetivo realizar uma avaliação dos serviços prestados por uma empresa de comercialização de máquinas agrícolas, visando agregar valor aos seus processos e operações de trabalho. Justifica-se a realização desta pesquisa pela importância da elaboração de estudos que visem aprimorar a qualidade dos processos e operações em uma empresa. Essa busca de resultados se torna relevante para avaliar as operações e os processos empresariais e para que, posteriormente, sejam realizadas adaptações, procurando cada vez mais adequar os serviços prestados para maior satisfação dos clientes.

O presente artigo encontra-se estruturado da seguinte forma: após a introdução apresenta-se o embasamento teórico do estudo abordando temas como a gestão de operações em serviços, a questão dos serviços e sua importância na economia, as características dos serviços, bem como a classificação dos mesmos e, ainda, a qualidade em serviços, a escala SERVQUAL e o comportamento do consumidor de serviços. O terceiro item contempla a metodologia utilizada para a realização do trabalho com suas devidas classificações. No quarto item encontram-se a análise e a discussão dos resultados, abordando a avaliação da qualidade dos serviços na empresa em estudo. Encerra-se o artigo com as considerações finais e as sugestões de pesquisas futuras que possam contribuir ainda mais com o tema.

\section{Gestão de operações em serviços}

Segundo Martins e Laugeni (2005, p. 6), “as atividades desenvolvidas por uma empresa visando atender seus objetivos de curto, médio e longo prazo se inter-relacionam, muitas vezes de forma extremamente complexa". Tais atividades, na tentativa de transformar insumos, como matérias-primas, em produtos e/ou serviços acabados, consomem recursos e nem sempre agregam valor ao produto final. É o objetivo da administração de operações a gestão eficaz dessas atividades, com isso, a administração das operações encontra-se em todas as áreas de atuação dos diretores, gerentes, supervisores e qualquer colaborador da empresa.

Os mesmos autores destacam que nas operações de serviços é necessário o encontro entre o fornecedor e o cliente e o local no qual se dá esse encontro é denominado de front office, ou seja, é o lugar onde o cliente recebe o serviço e o fornecedor fica frente a frente com o cliente, onde todo tipo de variabilidade e situações novas podem ocorrer, sendo o controle nesse tipo de situação muito 
difícil. Nesse contexto, torna-se cada vez mais relevante planejar os processos e operações produtivas para reduzir as deficiências de uma organização na sua prestação de serviços.

As empresas geralmente são estudadas como um sistema que transforma, via um processamento, entradas (insumo) em saídas (produtos) úteis aos clientes. Para que um sistema produtivo transforme insumos em produtos (bens e/ou serviços), ele precisa ser pensado em termos de prazos, em que planos são feitos e ações são disparadas com base nestes planos para que, transcorridos estes prazos, os eventos planejados pelas empresas venham a se tornar realidade (TUBINO, 2007).

Malhotra (2008) afirma que o desafio para as empresas hoje é satisfazer seus clientes por meio do desempenho excepcional de seus processos, portanto, avaliar o desempenho do processo também é necessário para administrar cadeias de valor. Neste contexto, para avaliar o desempenho dos processos produtivos, é relevante fazer uma ligação com o estudo da gerência da qualidade.

Para Martins e Laugeni (2005), ao longo de todo o desenvolvimento dos processos de fabricação de bens tangíveis estiveram presentes, sempre de forma crescente, os serviços. O setor de serviços emprega mais pessoas e gera maior parcela do Produto Interno Bruto (PIB) na maioria das nações do mundo. Dessa forma, passou-se a dar ao fornecimento de serviços uma abordagem semelhante a dada à fabricação de bens tangíveis. Foram incorporadas praticamente todas as técnicas até então usadas pela engenharia industrial. Ocorreu, pois, uma ampliação do conceito de produção, que passou a incorporar os serviços.

\subsection{Serviços e sua importância na economia}

Prass, Sant'Anna e Godoy (2010) destacam que a participação do setor de serviços vem crescendo ao longo dos anos, gerando cada vez mais empregos e oportunidades no mercado. Nesse sentido, Fitzsimmons e Fitzsimmons (2010) reforçam que os serviços estão no centro da atividade econômica de qualquer sociedade, onde a importância das atividades de serviços na sociedade pode ser demonstrada pela posição que ocupam na economia, seja através da participação no PIB seja na geração de empregos, e pela análise das tendências e transformações que a economia mundial está experimentando.

De acordo com Gianesi e Corrêa (1996), existem alguns fatores que propiciam o aumento da demanda por serviços, entre eles pode-se citar: o desejo de melhor qualidade de vida; mais tempo de lazer, a urbanização, tornando necessários alguns serviços; mudanças demográficas; mudanças socioeconômicas, aumento na sofisticação dos consumidores, levando a necessidades mais amplas de serviços; mudanças tecnológicas, que têm aumentado a qualidade dos serviços e criado serviços completamente novos. Os mesmos autores destacam ainda que as atividades de serviços exercem 
papel importante no desempenho de outros setores na economia, e o que se destaca é o setor industrial. E, ainda, resumem este papel em três categorias:

- Como diferencial competitivo: as atividades de serviços prestados ao cliente (como projeto, crédito, distribuição e assistência técnica) pelas empresas de manufatura têm atuado no sentido de diferenciar o pacote produto/serviço que a empresa oferece ao mercado, gerando um diferencial competitivo;

- Como suporte às atividades de manufatura: muitas das funções dentro das empresas de manufatura são, na verdade, operações de serviços (como recursos humanos, manutenção, processamento de dados), as quais são fundamentais para o desempenho competitivo da empresa;

- Como geradores de lucro: muitas atividades de serviços de empresas de manufatura podem desenvolver-se a um ponto que ultrapassem a mera função de apoio, passando a construir centros de lucro dentro das empresas.

As indústrias de serviços são a fonte de liderança econômica. Durante os últimos 30 anos, mais de 44 milhões de novos empregos foram criados no setor de serviços para absorver o afluxo de mulheres na força de trabalho e proporcionar uma alternativa para carência de oportunidades de emprego na manufatura (FITZSIMMONS; FITZSIMMONS, 2010).

Segundo Gianesi e Correa (1996), em todos os países desenvolvidos o setor de serviços ocupa posição de destaque na economia. Para evidenciar este fato têm sido utilizados os percentuais de participação do setor de serviço na ocupação de mão de obra e na geração do PIB. No caso dos dados relativos à estrutura percentual do PIB do Brasil, os dados do Instituto Brasileiro de Geografia e Estatística (IBGE), classificam como indústria as atividades de extração mineral, transformação, construção e serviços industriais de utilidade pública, enquanto no setor de serviços estariam incluídos comércio, transportes, comunicações instituições financeiras, administração pública, aluguéis e outros serviços. A importância crescente dos serviços na economia brasileira é evidente pelos dados apresentados no Anuário Estatístico do Brasil, que considera como atividade industrial o componente serviço do pacote formado por produtos e serviços que as empresas estão oferecendo ao mercado.

\subsubsection{Características dos serviços}

Para a realização de qualquer momento da verdade, que é quando o cliente tem contato com alguma parte da empresa, são necessários certos atributos, ou seja, o que se precisa para proporcionar serviços de qualidade (LAS CASAS, 2006). Ainda segundo o autor, estes atributos podem ser vistos de certa forma como requisitos essenciais para que os momentos da verdade ocorram de acordo com determinado nível de expectativa dos clientes. 
De acordo com Fitzsimmons e Fitzsimmons (2010), os clientes utilizam cinco dimensões para fazer julgamentos sobre a qualidade dos serviços, como se pode observar no Quadro 1, os quais baseiam-se na comparação entre o serviço esperado e o percebido. Conforme esses autores, a diferença entre a qualidade do serviço esperado e o percebido é uma medida da qualidade do serviço; a satisfação é negativa ou positiva.

\begin{tabular}{|c|c|c|}
\multicolumn{1}{c|}{ Quadro 1 - Dimensões para avaliação dos serviços } \\
\hline Dimensão & $\begin{array}{c}\text { Descrição } \\
\text { Confiabilidade }\end{array}$ & $\begin{array}{c}\text { É a capacidade de prestar o serviço prometido com confiança e exatidão. O desempenho de um } \\
\text { serviço confiável é uma expectativa do cliente e significa um serviço cumprido no prazo, sem } \\
\text { modificações e sem erros. }\end{array}$ \\
\hline Responsividade & $\begin{array}{c}\text { É a disposição para auxiliar os clientes e fornecer o serviço prontamente. Deixar o cliente } \\
\text { esperando, principalmente por razões não aparentes, cria desnecessariamente uma percepção } \\
\text { negativa da qualidade. Se ocorre uma falha em um serviço, a capacidade para recuperá-la } \\
\text { rapidamente e com profissionalismo pode criar muitas percepções positivas da qualidade. }\end{array}$ \\
\hline Segurança & $\begin{array}{c}\text { É o conhecimento e a cortesia dos funcionários bem como a sua capacidade de transmitir } \\
\text { confiança e confidencialidade. A dimensão segurança inclui as seguintes características: } \\
\text { competência para realizar o serviço, cortesia e respeito ao cliente, comunicação efetiva com o } \\
\text { cliente e a ideia de que o funcionário está realmente interessado no melhor para o cliente. }\end{array}$ \\
\hline Empatia & $\begin{array}{c}\text { É demonstrar interesse, atenção personalizada aos clientes. A empatia inclui as seguintes } \\
\text { características: acessibilidade sensibilidade e esforço para atender as necessidades dos clientes. } \\
\text { É a aparência das instalações físicas, equipamentos, pessoal e materiais para comunicação. A } \\
\text { condição do ambiente (por exemplo, limpeza) é uma evidência tangível do cuidado e da } \\
\text { atenção aos detalhes exibidos pelo fornecedor do serviço. Esta dimensão também pode } \\
\text { estender-se à conduta de outros clientes que estejam utilizando o serviço. }\end{array}$ \\
\hline
\end{tabular}
Fonte: Adaptado de Fitzsimmons e Fitzsimmons (2010)

Apesar de algumas diferenças entre os serviços e os problemas de definição, existem conforme Schmenner (1999), algumas características relevantes comuns a muitos setores de serviços, a saber:

a) Impossibilidade de fazer estoque: por sua natureza, o consumo de um serviço costuma ser quase simultâneo a sua produção. É praticamente impossível estocar um serviço, em função disso a escolha da capacidade ganha importância vital. O tamanho, o layout e a localização exata de uma operação de serviço são muitos importantes para gerar receita;

b) Produção e consumo fisicamente unidos: Geralmente os serviços são criados e entregues na hora. A intangibilidade do serviço resulta de um processo executado justamente onde se encontra o cliente. Em serviços, o controle da qualidade se torna mais importante, e para isso o treinamento e o bom relacionamento com os funcionários são especialmente importantes;

c) Entrada fácil no mercado: Boa parte das operações de serviço, o que não significa todas, requer pouco investimento de capital, unidades operacionais múltiplas ou desenvolvimento de tecnologia própria. Para muitos serviços, são poucas as barreiras à entrada no mercado, em função disso há uma disputa contínua pela posição e uma necessidade constante de pensar estrategicamente sobre o que está acontecendo; e 
d) Influências externas: Os serviços podem ser altamente afetados por influências externas, tais como avanços tecnológicos, regulamentação governamental e aumentos de preço da energia.

No entendimento de Martins e Laugeni (2005), os serviços apresentam basicamente as seguintes características: alto contato com o cliente, participação do cliente no processo, pericibilidade, não estocável, mão de obra intensiva, intangibilidade, dificuldade de ser medir produtividade e dificuldade em se medir qualidade.

Mesmo sendo invisível para o mercado, a função das operações de serviços em uma empresa normalmente é importantíssima. Por isso, em um ambiente instável e propício à geração de novos concorrentes, essas características devem ser analisadas e ajustadas para que a empresa consiga alcançar seus objetivos e conseguir seu espaço no mercado.

\subsubsection{Classificação dos serviços}

Em busca de uma classificação para os processos de serviços, Silvestro et al (1992) propõem utilizar seis dimensões: foco em pessoas ou equipamentos, grau de contato com o cliente, grau de personalização do serviço, grau de julgamento pessoal dos funcionários, foco no produto ou no processo e front office ou back room como fonte de valor adicionado. $\mathrm{O}$ mesmo autor classificou os serviços em: serviços profissionais, loja de serviço e serviços de massa.

Serviços profissionais são aqueles em que o cliente está geralmente buscando no fornecedor do serviço uma capacitação de que não dispõe. Nesse tipo de serviço o processo de prestação dá ênfase às pessoas (que geralmente detêm a capacitação que o cliente deseja), enquanto os equipamentos são utilizados apenas como ferramenta de apoio. Nos serviços profissionais a utilização mais intensiva de equipamentos está vinculada a sua flexibilidade, já que esse processo visa à personalização do serviço a clientes específicos. Os serviços profissionais proporcionam alto grau de contato com os clientes. Esse contato faz com que o valor do serviço seja produzido prioritariamente com a presença do cliente, colocando grande ênfase no processo de prestação do serviço, sendo, às vezes, maior do que o resultado. Através da personalização e da grande ênfase na utilização de pessoas para a prestação de serviço, esse processo requer que se dê alto grau de autonomia aos funcionários de contato com o cliente (GIANESI; CORRÊA, 1996).

Para os mesmos autores, o processo denominado loja de serviços é aquele intermediário no contínuo entre os serviços profissionais e os serviços de massa e este processo caracteriza-se por um volume maior de clientes processados por dia. O cliente que tem um contato com a empresa e está geralmente interessado tanto no resultado do serviço como no processo, onde nesse tipo de processo há certo grau de personalização do serviço, mas existe a oportunidade de padronizar as operações, exigindo assim, menor autonomia do pessoal de contato. 
O serviço de massa é aquele em que existe atendimento ao maior número de clientes por unidade de tempo, sendo serviços pouco personalizados, com alto grau de padronização de operações. E essa padronização favorece o uso de equipamentos para a produção do serviço, no qual, embora geralmente seja necessária a presença do cliente, o grau de contato é relativamente baixo e impessoal. Ressalta-se que os serviços podem ser distribuídos por grupos de atividades e classificados por critérios de durabilidade e há também a classificação de serviços com base na relação tangibilidade/intangibilidade. Todavia, quando se refere a serviços, há muitas diferenças na comercialização de cada setor (LAS CASAS, 2006).

Segundo a classificação do IBGE, os serviços podem ser: serviços de alojamento e alimentação; serviços de reparação, confecção e manutenção; serviços de higiene pessoal; serviços de diversão; serviços auxiliares da agricultura e da pecuária; serviços auxiliares de atividade financeira; serviços auxiliares de transporte; serviços técnicos especializados à construção; serviços de limpeza; serviços pessoais e serviços auxiliares diversos. Esta classificação do IBGE permite que se analise a diversidade do setor de serviços.

\subsection{Qualidade em serviços}

A respeito da qualidade em serviços, segundo Karl (1992 apud LAS CASAS, 2006), esta é a capacidade que uma experiência ou qualquer outro fator tem para satisfazer uma necessidade, resolver um problema ou fornecer benefícios a alguém.

E no atual ambiente competitivo, a qualidade em serviço tem sido reconhecida como um componente estratégico essencial para as empresas que almejam ter sucesso no seu negócio e sobreviver no mercado (HUME, 2008; AL TAMIMI; JABNOUN, 2006; SPRENG; MACKENGENZIE; OLSHAVASKY, 1996). Sob esse enfoque, Camarero (2007) e Solvang (2007) defendem que as empresas que fornecem altos níveis de qualidade em serviço estão mais propensas a satisfazer e reter seus clientes.

Assim sendo, Frazier (2001) cita que a gerência da qualidade é tão importante para as organizações prestadoras de serviços quanto para as organizações manufatureiras. Para a maioria das empresas, a qualidade superior é o centro de sua estratégia de negócios. Obter um produto de qualidade quase perfeita é visto como o meio principal de conquistar uma parcela maior do mercado.

Já para Gianesi e Correa (1996), qualidade em serviços pode ser definida como o grau em que as expectativas do cliente são atendidas e/ou excedidas por sua percepção do serviço prestado.

Fitzsimmons e Fitzsimmons (2010) afirmam que em serviços a avaliação da qualidade surge ao longo do processo da prestação, que geralmente ocorre no encontro entre um cliente e um funcionário da linha de frente. A satisfação do cliente com a qualidade do serviço pode ser definida 
pela comparação da percepção do serviço prestado com a expectativa do serviço desejado. Conforme os autores, quando se excede a expectativa, o serviço é percebido como de qualidade excepcional, e também como uma agradável surpresa. Quando, no entanto, não se atende às expectativas, a qualidade do serviço passa a ser inaceitável.

O desempenho e a qualidade do processo devem ser preocupação de todos, onde a qualidade dos produtos e serviços não é definida ou determinada pelas empresas produtoras, ela é determinada pelos clientes. As expectativas dos clientes em relação à qualidade são afetadas por vários fatores, incluindo produtos dos concorrentes e mudam com o decorrer do tempo. Os produtos e serviços devem, portanto, ser melhorados com o tempo para atender as mudanças nas expectativas dos clientes (MALHOTRA, 2008).

Frazier (2001) complementa que a qualidade de um produto ou serviço é a percepção do cliente do grau que o produto ou serviço atende a suas expectativas e, ao avaliar a qualidade, os clientes, levam em consideração vários aspectos diferentes dos produtos e serviços. As empresas têm de procurar os clientes para definir os padrões de medida da qualidade, as pesquisas e sugestões de clientes podem ser usadas como dados dos clientes a respeito da qualidade. No Quadro 2, o autor propõe algumas atividades que são necessárias para obter a qualidade:

Quadro 2 - Atividades necessárias para a obtenção da qualidade

\begin{tabular}{|c|c|}
\hline Atividades & Descrição \\
\hline $\begin{array}{c}\text { Qualidade do projeto } \\
\text { Capacidade dos processos de } \\
\text { produção }\end{array}$ & $\begin{array}{c}\text { Depois de identificar quem são os clientes, a empresa tem de determinar o } \\
\text { que seus clientes querem de seus produtos e serviços. Depois seus produtos e } \\
\text { serviços são elaborados para exibir os atributos necessários para atender as } \\
\text { expectativas dos clientes. }\end{array}$ \\
$\begin{array}{c}\text { Os processos de produção têm de ser elaborados e desenvolvidos para ter } \\
\text { capacidade de produzir produtos com os atributos desejados pelos clientes. }\end{array}$ \\
$\begin{array}{c}\text { Os locais de produção devem então ser dirigidos para produzir produtos e } \\
\text { serviços que atendem as especificações de projeto e desempenho voltadas } \\
\text { para as expectativas de qualidade dos clientes. }\end{array}$ \\
\hline $\begin{array}{c}\text { Todos os contatos entre os clientes e as empresas têm de ser administrados } \\
\text { de forma que os clientes sintam que foram tratados de forma justa e educada, } \\
\text { com suas necessidades sendo atendidas imediatamente e com interesse. }\end{array}$ \\
\hline $\begin{array}{c}\text { Toda empresa tem de trabalhar com afinco para fazer o que é necessário para } \\
\text { projetar, produzir e dar assistência técnica aos produtos e serviços que } \\
\text { atendam as expectativas dos clientes. Deve-se ativar mecanismos para } \\
\text { melhorar constantemente cada uma das facetas da organização com o intuito } \\
\text { de criar um grau cada vez maior de satisfação dos clientes. }\end{array}$ \\
\hline
\end{tabular}

Fonte: Adaptado de Frazier (2001)

Para Slack (1999), a qualidade é vista como sendo tão importante para a maioria das operações produtivas, sendo que existem várias formas pelas quais os melhoramentos da qualidade podem afetar outros aspectos do desempenho da produção. Os dois contribuintes da lucratividade podem ser melhorados pela qualidade mais alta e as receitas podem ser incrementadas por melhores vendas e por preços mais altos no mercado, onde ao mesmo tempo, os custos podem ser reduzidos pela melhor eficiência, produtividade e uso do capital. 
Há custos associados com a qualidade do produto e do serviço. Alguns desses custos estão associados com evitar má qualidade e outros surgem depois da má qualidade ocorrer. Segundo Frazier (2001) entre esses custos estão:

a) Sucata e retrabalho: quando os produtos se revelam defeituosos ainda na fase de produção, eles têm de ser sucateados ou consertados;

b) Produtos defeituosos nas mãos dos clientes: quando os produtos são enviados aos clientes, os custos podem ser enormes e difíceis de medir. Entre esses custos podem estar os custos de garantia, processos ou acordos de responsabilidade pelo produto e os custos de devolução ou recolhimento e perda de negócio e freguesia;

c) Detectar defeitos: o custo de todas as atividades que visam produtos e serviços que estão de acordo com as especificações antes de esses serem enviados para os clientes. Ele inclui o custo de inspecionar, testar e outras atividades de controle da qualidade; e

d) Evitar defeitos: o custo de treinar, representar graficamente o desempenho da qualidade para estudar tendências, revisar projetos de produtos, fazer mudanças nos processos de produção, trabalhar com fornecedores e outras atividades que visem melhorar a qualidade e evitar defeitos.

A gestão da qualidade total é uma filosofia que enfatiza três princípios para se alcançar níveis elevados de desempenho e qualidade do processo. Esses princípios estão relacionados à satisfação do cliente, ao envolvimento do funcionário e a melhoria contínua do desempenho. Os clientes internos ou externos estão satisfeitos quando suas expectativas em relação a um serviço ou produto foram atendidas ou superadas. Muitas vezes, os clientes usam o termo qualidade para descrever seu nível de satisfação em relação a um serviço ou produto (MALHOTRA, 2008).

De acordo com Russomano (2000), um dos elementos importantes é o envolvimento dos funcionários, o que inclui mudar a cultura organizacional e encorajar o trabalho em equipe, portanto o desafio da administração da qualidade é instilar em todos os funcionários uma consciência da importância da qualidade e motivá-los a aperfeiçoá-la.

Segundo Malhotra (2008), a melhoria contínua baseada no conceito japonês kaizen, é a filosofia de se buscar continuamente maneiras para aperfeiçoar os processos. Ela envolve identificar benchmarks de prática de excelência, ou padrões de excelência, e estimular no funcionário um sentimento de propriedade do processo. $\mathrm{O}$ foco pode ser a redução do tempo necessário para processar solicitações de empréstimos em um banco, da qualidade de refugo gerada em uma máquina ou do número de acidentes de trabalho. A melhoria contínua também pode focalizar problemas com os clientes ou fornecedores, onde os fundamentos de melhoria contínua são as convicções de que, potencialmente, qualquer aspecto de um processo pode ser aperfeiçoado e de que as pessoas mais diretamente envolvidas com um processo estão em melhor posição para identificar as mudanças que devem ser realizadas. 
A avaliação entre o serviço esperado e o percebido é um processo rotineiro de retorno de informação do cliente para empresa. É muito importante a organização conseguir captar quais são as falhas cometidas para então realizar um planejamento para que estas sejam eliminadas. Fitzsimmons e Fitzsimmons (2010) apresentam cinco falhas que devem ser seguidos no projeto de um novo processo de serviço:

- Falha 1: que é a pesquisa de mercado, surge da falta de compreensão por parte do setor administrativo, do modo como os clientes formulam suas expectativas como base em uma série de fontes: anúncios, experiências anteriores com a empresa, necessidades pessoais e comunicação com amigos. Estratégias para minimizar essas falhas incluem a melhoria na pesquisa de mercado, melhor comunicação entre a administração e seus empregados;

- Falha 2: que é projeto do serviço, pode resultar de uma falta de comprometimento da administração com a qualidade do serviço ou de uma percepção de impossibilidade de atender as expectativas dos clientes. Para eliminar essa falha aconselha-se o estabelecimento de metas e padronização na prestação dos serviços;

- Falha 3: diz que a conformidade ocorre porque o serviço efetivamente prestado não atende as especificações estabelecidas pela administração. A Falha 3 pode originar-se através da seleção inadequada de funcionários, treinamento inadequado e divisões inapropriadas das tarefas;

- Falha 4: é a comunicação. As expectativas dos clientes a respeito de um serviço são formadas por anúncios na mídia e outras divulgações realizadas pela empresa. Essa falha é caracterizada pela discrepância entre o serviço prestado e as comunicações externas, na forma de promessas exageradas e da falta de informação fornecida; e

- Falha 5: é referente à satisfação do cliente. Essa falha depende da minimização das quatro falhas que estão associadas à prestação do serviço.

Em meio às constantes mudanças ocorridas no ambiente empresarial, a avaliação dos serviços e conhecimento das falhas torna-se essencial para a organização ter conhecimento dos sucessos e fracassos na prestação de serviço. Essa avaliação proporciona um feedback entre os clientes e a empresa.

\subsubsection{Escala SERVQUAL}

Berry, Zeithaml e Parasuraman desenvolveram um instrumento de pesquisa, denominado de Servqual. Trata-se de um meio, uma metodologia para avaliar as percepções dos clientes em relação aos serviços, sendo um instrumento de escala múltiplo, com alto nível de confiabilidade e validez. Na escala SERVQUAL é feita uma comparação entre a expectativa e a percepção do serviço no ponto de vista do cliente. No que se refere às expectativas, são feitas declarações dirigidas a identificar as expectativas gerais dos usuários em relação aos serviços e, em relação às percepções, 
são feitas declarações para medir a percepção da qualidade do serviço relativa a uma determinada empresa da categoria de serviço analisada (SCHMENNER, 1999).

Segundo Gianesi e Corrêa (1996), os serviços dificilmente podem ser avaliados antes da compra, a avaliação pode ser dada durante o processo de prestação de serviço ou, somente após ser conhecido o resultado. A avaliação que o cliente faz, durante ou após o término do processo, se dá através da comparação entre o que o cliente esperava (expectativa) e o que ele percebeu do serviço prestado (percepção).

Para Fitzsimmons e Fitzsimmons (2010, p. 142) "medir a qualidade dos serviços é um desafio, pois a satisfação dos clientes é determinada por muitos fatores intangíveis". A qualidade em serviços contém muitas características psicológicas, ao contrário de um produto com características físicas que podem ser objetivamente mensuradas. Em função de o serviço ser intangível, essa avaliação é mais significativa para prestação de serviço. A formação das expectativas do cliente antes da compra não pode basear-se em uma imagem real, dependendo, entre outros fatores, da comunicação transmitida aos consumidores. A qualidade em serviços frequentemente estende-se além do encontro imediato e essas múltiplas dimensões da qualidade em serviços são captadas pela ferramenta SERVQUAL, que é uma ferramenta valiosa para pesquisar a satisfação do cliente com base no modelo de falha na qualidade em serviços.

Guarienti et al. (2006, p. 7) argumentam que:

Considerando expectativas versus percepções, para a análise da qualidade dos serviços recebidos, destaca-se que a ferramenta SERVQUAL é uma técnica que facilita a interpretação dos dados e, comparando com trabalhos da literatura, os resultados podem ser considerados confiáveis para tomada de decisão pela gerência da empresa.

Nas palavras de Oliveira, Leal e Fenerich (2013, p. 165), “a qualidade dos serviços está diretamente relacionada à plena satisfação do cliente. Para que isso aconteça, o segredo é concentrar-se nas necessidades e desejos do cliente oferecendo um serviço que atenda ou exceda suas expectativas".

Gianesi e Corrêa (1996) reforçam essa ideia ao trazer que alguns autores defendem a hipótese de que o cliente se baseia em suas expectativas para avaliar a qualidade de um serviço, levando a ideia de que o fornecedor do serviço deve visar atender as expectativas do cliente e não as suas necessidades. Outros autores preferem tratar do atendimento das necessidades dos clientes; outros ainda tratam tanto as necessidades como as expectativas. Pode-se considerar que as necessidades de um cliente são menos mensuráveis do que suas expectativas. Em uma pesquisa, o que o cliente expõe são as suas expectativas em relação a um serviço e determinar as necessidades dos clientes envolve certo grau de julgamento de valor por parte do fornecedor do serviço que 
pretende identificá-las, podendo provocar equívocos, se o fornecedor do serviço achar o que os clientes precisam.

Os autores descrevem ainda que, dada a importância da formação das expectativas do cliente para avaliação que fará da qualidade do serviço comprado, é útil que se analise como essas expectativas são formadas para que se possa avaliar o poder de atuação do fornecedor do serviço neste importante componente de avaliação feita pelo cliente e, consequentemente, do poder de competitividade. Por isso, destacam quatro fatores que podem influenciar nas expectativas do cliente, conforme exposto no Quadro 3.

\begin{tabular}{|c|c|}
\hline Fatores & Características \\
\hline Comunicação boca a boca & $\begin{array}{l}\text { Representa as recomendações que os clientes recebem de terceiros, outros clientes já } \\
\text { receberam o serviço do fornecedor considerado e/ou de outros. }\end{array}$ \\
\hline Necessidades pessoais & $\begin{array}{l}\text { As necessidades pessoais dos clientes são o principal formador de suas expectativas, já } \\
\text { que é visando atender a estas necessidades que os clientes procuram um serviço. }\end{array}$ \\
\hline Experiência anterior & $\begin{array}{l}\text { Se as expectativas dos clientes são influenciadas por sua experiência anterior, o } \\
\text { fornecedor do serviço pode influenciá-las através da consistência do serviço prestado. } \\
\text { Clientes de empresas de serviços que têm alta consistência sabem exatamente o que } \\
\text { esperar nas ocasiões em que repetem a compra do serviço. }\end{array}$ \\
\hline Comunicação externa & $\begin{array}{l}\text { Outro fator que influencia os clientes no momento de optar por um serviço é a } \\
\text { comunicação externa, boca a boca exercida por outros clientes que já compraram o } \\
\text { serviço, propagandas realizada pela empresa etc. }\end{array}$ \\
\hline
\end{tabular}

Fonte: Adaptado de Gianesi e Corrêa (1996)

Entre os fatores que podem influenciar as expectativas dos clientes é a atuação dos fornecedores de serviço sobre as necessidades dos clientes e não se trata de discutir a possibilidade de o fornecedor alterar as necessidades de certo cliente, e sim, a possibilidade de restringir o tipo de cliente a ser atendido por determinado sistema de operações. Através dessa restrição é possível identificar o tipo de cliente e as suas expectativas em relação ao serviço, a empresa consegue com isso informações que revelam se está ou não preparada para executar esse tipo de serviço proporcionando qualidade total no resultado final. Isso pode ser feito através de uma estratégia de segmentação, foco e seleção de clientes. Já em relação à percepção dos serviços prestados, os autores Gianesi e Corrêa (1996, p. 86) afirmam que "a percepção que o cliente tem do serviço prestado é formada por dois fatores principais: a prestação do serviço e a comunicação transmitida ao cliente durante ou após o processo". A parte do serviço que está sendo prestada, a comunicação transmitida ao cliente pode modificar a percepção, pois muitas vezes os clientes não estão cientes de tudo o que acontece no sistema de operações (GIANESI; CORRÊA, 1996).

Para os mesmos autores, a prestação do serviço é a principal responsável pela percepção do cliente em relação ao serviço. A expressão "momento da verdade" foi criada por Normann em 1984, e ela simboliza o momento de contato entre o fornecedor do serviço e o cliente. A percepção do cliente é formada em cada momento da verdade, ou seja, em cada momento que o cliente entra em contato com qualquer aspecto da empresa fornecedora. Em cada momento da verdade o cliente irá 
comparar a percepção do serviço prestado com suas expectativas iniciais, julgando assim a qualidade do serviço. Portanto, determinar os critérios os quais os clientes avaliam os serviços é fundamental para que o fornecedor possa priorizar seus esforços para gerar assim uma percepção favorável ao cliente.

Já os autores Fitzsimmons e Fitzsimmons (2010) e Chaker e Jabnoun (2010) explicam que a SERVQUAL é um instrumento para avaliar as cinco dimensões da qualidade em serviços (confiabilidade, responsividade, segurança, empatia e aspectos tangíveis). Para aplicação dessa ferramenta têm-se duas etapas principais: inicialmente, faz-se um registro das expectativas dos clientes para determinada classe de serviços e, na sequência, computam-se as percepções dos clientes sobre uma determinada organização. O modelo de Escala SERVQUAL utilizada por Fitzsimmons e Fitzsimmons (2010) pode ser visualizado no Quadro 4, onde o mesmo contempla questionamentos que estão relacionados às cinco dimensões da qualidade em serviços.

Quadro 4-O instrumento SERVQUAL

1. As empresas devem possuir equipamentos modernos.

2. Suas instalações físicas devem ser visualmente atraentes.

3. Seus funcionários devem estar bem vestidos e ter boa aparência.

4. A aparência das instalações físicas dessas empresas deve ser mantida de acordo com o tipo de serviço oferecido.

5. Quando essas empresas se comprometem em fazer algo em um prazo determinado, devem cumpri-lo.

6. Quando os clientes enfrentam problemas, essas empresas devem ser solidárias e prestativas.

7. Essas empresas devem ser confiáveis.

8. As empresas devem fornecer seus serviços nos prazo prometido.

9. As empresas devem manter seus registros atualizados.

10. Não se deve esperar que as empresas comuniquem aos clientes exatamente quando os serviços estarão concluídos.

11. Não é realista os clientes esperarem serviço imediato dos funcionários dessas empresas.

12. Seus funcionários nem sempre precisam estar dispostos a ajudar os clientes.

13. Não há problema se os funcionários estiverem muito ocupados para responder prontamente as solicitações dos clientes.

14. Os clientes devem poder confiar nos funcionários dessas empresas.

15. Os clientes devem poder se sentir seguros em suas transações com os funcionários dessas empresas.

16. Seus funcionários devem ser gentis.

17. Seus funcionários devem receber o apoio adequado de suas empresas para executar bem as suas tarefas.

18. Não deve ser esperado que essas empresas deem atenção individual aos clientes.

19. Não se pode esperar que os funcionários deem atenção personalizada aos clientes

20. Não é realista esperar que os funcionários saibam quais as necessidades dos clientes.

21. Não é realista esperar que essas empresas estejam profundamente interessadas no bem-estar do cliente.

22. Não se deveria esperar que essas empresas operassem em horários convenientes para todos os seus clientes.

Fonte: Fitzsimmons e Fitzsimmons (2010, p. 143)

Essa ferramenta foi projetada e validada para o uso em uma variedade de encontros de serviços. Nesse sentido, Fitzsimmons e Fitzsimmons (2010) sugerem muitas aplicações para a SERVQUAL, mas a sua função principal é identificar as tendências da qualidade em serviços por meio de pesquisas periódicas com os clientes. A SERVQUAL pode ser utilizada para determinar se alguma unidade apresenta serviço de qualidade insatisfatório, para então dedicar-se a correções. 


\subsection{Comportamento do consumidor de serviços}

Antunes e Simões (2013, p. 416) entendem que "nos últimos anos, a opinião do consumidor ganhou um espaço privilegiado na administração das corporações". E acrescentam que "[...] as empresas que não buscam satisfazer as necessidades de seus clientes não conseguem sobreviver no mercado competitivo".

Sob esse enfoque, Las Casas (2006) comenta que no caso dos consumidores de mercadorias e serviços as empresas passaram a se preocupar com os mesmos, procurando entendê-los e avaliálos para elaborar planos de marketing mais adequados. Entretanto, o processo de entendimento do consumidor não é uma tarefa fácil, pois os clientes são pessoas que sofrem muitas influências. No processo de compra de serviço, existem dois personagens principais que estão presentes no mercado de consumo: o usuário, que é aquele que vai consumir o serviço, e o decisor, que é aquele que toma a decisão no processo de compra.

E vários são os fatores que podem influenciar o cliente na hora de optar por um serviço, sendo que o primeiro parte de um processo de identificação das necessidades e o segundo, que também influencia, são as características dos clientes e a sua motivação para ir a busca desse serviço. Existem ainda outros fatores que podem despertar uma necessidade, sendo externa a pessoa, são os estímulos provocados pelas variáveis sociais, culturais, econômicas e demais variáveis incontroláveis (LAS CASAS, 2006).

Assim sendo, Gianesi e Corrêa (1996) complementam descrevendo os quatro grupos básicos de fatores que influenciam o consumidor na hora de optar pelo serviço e que devem ser considerados, conforme apresentado no Quadro 5.

\begin{tabular}{|c|c|}
\multicolumn{2}{c|}{ Quadro 5 - Fatores que influenciam o consumidor } \\
\hline Fatores & Características \\
\hline Culturais & $\begin{array}{r}\text { Referem-se, principalmente, ao conjunto de valores aos quais uma pessoa está exposta } \\
\text { desde a infância e que são incorporados. Esse fator depende também da subcultura, } \\
\text { influenciada pela nacionalidade, grupo racial, religioso e pela região geográfica. }\end{array}$ \\
\hline Sociais & $\begin{array}{r}\text { Referem-se aos grupos de referência dos consumidores, ou seja, grupos que direta ou } \\
\text { indiretamente influenciam o comportamento e as atitudes dos consumidores. }\end{array}$ \\
\hline Pessoais & $\begin{array}{c}\text { A análise dos fatores pessoais é importante para a compreensão do processo de decisão do } \\
\text { cliente, mas os fatores psicográficos ou comportamentais são considerados mais relevantes. }\end{array}$ \\
\hline Psicológicos & $\begin{array}{c}\text { Existem quatro fatores psicológicos que influenciam no comportamento do consumidor: } \\
\text { motivação, percepção, aprendizado e convicções e atitudes. }\end{array}$ \\
\hline
\end{tabular}

Fonte: Adaptado de Gianesi e Corrêa (1996)

Os principais objetivos dos provedores e profissionais de marketing de serviço são o desenvolvimento e a oferta de serviços que atendam às necessidades e expectativas dos clientes, o que garante a própria sobrevivência econômica. Para alcançar esses objetivos, as prestadoras de serviço precisam entender a maneira como os consumidores escolhem, presenciam e avaliam a oferta de serviço (ZEITHAML; BITNER; GREMLER, 2001). 
Segundo Las Casas (2006, p. 185), "uma das fontes mais importantes para a informação dos produtos e serviços existentes no mercado é a propaganda" e isso significa que os consumidores procuram verificar anúncios e comerciais antes de decidirem que produto comprar ou solicitar algum tipo de serviço. Os clientes buscam informações também em outras fontes, que podem ser internas sendo aquelas que estão na memória, e externas, que são provenientes de diversos meios, como prestadores de serviço, folhetos, amigos e conhecidos.

O comportamento do consumidor após a compra do serviço depende de seu grau de satisfação com o resultado, quanto mais satisfeito com o serviço, maior será a probabilidade de repetição. O consumidor percebe certo risco na compra de serviços, isso em função da impossibilidade ou dificuldade de avaliá-lo antes da compra. A experimentação de um serviço, acompanhada de satisfação com os resultados, reduz o risco percebido pelo consumidor, favorecendo a repetição da compra do serviço do mesmo fornecedor. Os consumidores usam os preços e as instalações físicas como as maiores pistas da qualidade do serviço, o que traz especial importância para toda e qualquer evidência física que esteja ao alcance da percepção do consumidor, sejam instalações, equipamentos, bens facilitadores, funcionários e outros consumidores (GIANESI; CORRÊA, 1999).

\section{Metodologia}

A presente pesquisa, quanto à natureza, classifica-se como quantitativa, "que é determinada em relação aos dados ou proporção numérica" (FACHIN, 2001, p. 79) e qualitativa, que segundo Malhotra (2001) visa alcançar a compreensão qualitativa das razões e motivações subjacentes.

No que tange aos objetivos a pesquisa caracteriza-se como descritiva. Na concepção de Gil (2010), as pesquisas descritivas têm como objetivo primordial a descrição das características de determinadas populações ou fenômenos, sendo que uma delas está na utilização de técnicas padronizadas de coleta de dados, tais como o questionário e a observação sistemática.

Ainda em relação à classificação desta pesquisa quanto aos procedimentos técnicos, este caracteriza-se como um estudo de caso, sendo este na visão de Gonsalves (2007) o tipo de pesquisa que privilegia um caso em particular, uma unidade para análise de um fenômeno.

Quanto aos procedimentos e técnicas de trabalho, em um primeiro momento, utilizou-se da pesquisa bibliográfica. Martins (2010) descreve a pesquisa bibliográfica como o ponto de partida de toda pesquisa, que consiste no levantamento de informações feito a partir de material coletado em livros, revistas, artigos e em outras fontes escritas, devidamente publicadas.

Posteriormente, com o propósito de realizar a pesquisa de avaliação dos serviços prestados pela empresa, utilizou-se a aplicação da ferramenta SERVQUAL através da aplicação de um questionário, elaborado conforme o modelo sugerido pelos autores Fitzsimmons e Fitzsimmons 
(2010), em uma amostra por acessibilidade, composta por 40 clientes da empresa em estudo. Os dados foram tabuldados com o auxílio do software Sphinx $-\mathrm{V} 5^{\circledR}$. Após, os resultados obtidos foram analisados sob a ótica qualitativa.

\section{Descrição dos serviços prestados pela empresa}

O presente estudo foi realizado em uma empresa de comercialização de máquinas agrícolas, inaugurada em 2001, e atualmente a sua área de atuação abrange mais de trinta municípios. Os principais serviços prestados são serviços de mecânica em colheitadeiras, tratores e plantadeiras e a empresa possui ainda um amplo ambiente em que busca atender as necessidades de seus clientes, oferecendo um ótimo suporte no processo de pós-vendas.

A empresa conta em seu estabelecimento com um setor de peças onde estão disponibilizadas várias peças em estoque para que no momento em que seja solicitado um serviço de mecânica este possa ser realizado com rapidez e eficiência, evitando perda de tempo em encomendas. A instituição utiliza um sistema que facilita localizar e ver a disponibilidade em estoque e os respectivos valores e, no setor de peças, são realizados orçamentos sem custo e na falta de alguma peça, logo é informado o tempo para que a mesmo chegue até a empresa.

Como citado anteriormente, o principal serviço prestado pela empresa é referente à mecânica em colheitadeiras, tratores e plantadeiras. No momento em que é efetuada uma, o cliente já recebe a informação de que a empresa presta um atendimento pós-venda, a empresa inclusive oferece assistência técnica especializada em uma determinada marca de maquinários agrícolas, oferecendo profissionais capacitados para realizar esses tipos de serviços como: revisões, manutenções, consertos, trocas de peças, troca de óleo, manutenção na pintura dos tratores e limpeza profunda são alguns serviços prestados pela empresa. Esse tipo de prestação de serviço é classificado como serviços profissionais, ou seja, são aqueles em que o cliente está geralmente buscando no fornecedor do serviço uma capacitação que não dispõe.

A empresa disponibiliza serviço de massa, que é aquele em que existe atendimento ao maior número de clientes por unidade de tempo. Limpezas profundas, que são internas nos motores dos maquinários, são classificadas como serviço de massa, pois podem ser prestados com mais de uma unidade, não comprometendo o maquinário e o serviço. A instituição possui como diferencial a disponibilidade de um grupo de funcionários que atendem e dão suporte aos clientes em seus respectivos negócios ou residências. $\mathrm{Na}$ empresa ficam fixos alguns funcionários, mas o que ocorre com maior frequência são as visitas nas localidades dos clientes, principalmente em época de safra. Esse atendimento personalizado ocorre em função da dificuldade e demora em transportar um maquinário até a empresa. Contudo, certos serviços precisam ser realizados na empresa, em função dos equipamentos e ambiente mais apropriado. 
Quando existe a urgência em um serviço, a empresa presta atendimento e se responsabiliza em trazer e devolver o maquinário ao cliente, ficando este sem envolvimento algum no processo de transporte e manutenção. Atualmente, a empresa possui nas seis lojas do grupo aproximadamente seis mil clientes. Esse elevado número de clientes é em função da empresa possuir a melhor estrutura e ficar localizada no centro do Rio Grande do Sul, facilitando a locomoção dos maquinários.

Salienta-se que a empresa investe cada vez mais em recursos em pós-venda para que possa disponibilizar serviços de qualidade aos equipamentos, peças de reposição, ferramentas adequadas e treinamentos aos funcionários. Ao comprarem produtos comercializados os clientes sabem que estarão adquirindo equipamentos de alta tecnologia e desempenho e ressalta-se, inclusive, que a justificativa de quem compra é a grande performance que o produto apresenta no campo, a disponibilidade de peças de reposição e assistência técnica de alta capacitação. A instituição busca uma parceria com seus clientes, para que os mesmos possam revisar seus equipamentos fora de garantia, disponibilizando a sua equipe de suporte de pós- venda.

\subsection{Avaliação da qualidade dos serviços prestados pela empresa}

Na sequência, apresentam-se os resultados em relação à expectativa e percepção dos vinte e um itens analisados na pesquisa realizada. As variáveis analisadas foram avaliadas em relação à expectativa do cliente em relação ao serviço prestado e, posteriormente questionou-se a percepção do cliente após a execução do serviço. Por isso, os resultados estão dispostos, inicialmente, conforme a expectativa e, posteriormente, a percepção em relação ao mesmo aspecto.

Percebe-se na Tabela 1 os resultados quanto à expectativa dos clientes em relação às instalações da empresa, se as mesmas são adequadas e se o ambiente de trabalho é adequado.

Tabela 1 - Expectativa: instalações/ambiente interno adequados

\begin{tabular}{cc}
\hline Instalações/ambiente interno adequado & Percentual \\
\hline Ótimo & $92,50 \%$ \\
Muito bom & $5,00 \%$ \\
Bom & $2,50 \%$ \\
Regular & $0,00 \%$ \\
Péssimo & $0,00 \%$ \\
Total & $100 \%$ \\
\hline
\end{tabular}

Fonte: Autoria própria (2011)

Observa-se na Tabela 1 que 92,50\% dos pesquisados tinham a expectativa de serem ótimas as instalações e ambiente interno da empresa. Outros 5\% pensam ser muito bom o item avaliado e 2,5\% acham bom. Nota-se que a maioria dos pesquisados possuem uma ótima expectativa em relação às instalações e ao ambiente de trabalho da empresa. Isso pode ser observado através dos dados da Tabela 2, que apresenta a percepção dos pesquisados em relação às instalações e ambiente interno da empresa. 
Tabela 2 - Percepção: instalações/ambiente interno adequados

\begin{tabular}{cc}
\hline Instalações/ambiente interno adequado & Percentual \\
\hline Não responderam & $2,50 \%$ \\
Ótimo & $17,50 \%$ \\
Muito bom & $52,50 \%$ \\
Bom & $25,00 \%$ \\
Regular & $2,50 \%$ \\
Péssimo & $0,00 \%$ \\
Total & $100 \%$ \\
\hline
\end{tabular}

Fonte: Autoria própria (2011)

De acordo com os dados da Tabela 2, é possível identificar em relação à percepção dos pesquisados, que apenas 17,5\% consideram ótimas as instalações e o ambiente interno da empresa, outros $52,5 \%$ consideram muito bom a avaliação do item, enquanto que $25 \%$ pensam ser bom e apenas $2,5 \%$ consideram regular.

Pela comparação entre a expectativa e a percepção do item instalações e ambiente de trabalho adequado, observa-se uma discrepância/gap em relação aos resultados. A maioria dos pesquisados tinha alta expectativa sobre o item, o que acabou não se confirmando após o contato com a empresa. Seria importante que a empresa tivesse uma atenção especial em relação a este fator, providenciando melhorias como mais espaço para acomodações.

Com a apresentação da Tabela 3 verificaram-se os resultados referentes às expectativas dos clientes da empresa em relação ao pronto atendimento na recepção.

Tabela 3 - Expectativa: pronto atendimento na recepção

\begin{tabular}{cc}
\hline Pronto atendimento recepção & Percentual \\
\hline Não responderam & $5,00 \%$ \\
Ótimo & $80,00 \%$ \\
Muito bom & $12,50 \%$ \\
Bom & $0,00 \%$ \\
Regular & $2,50 \%$ \\
Péssimo & $0,00 \%$ \\
Total & $100 \%$ \\
\hline
\end{tabular}

Fonte: Autoria própria (2011)

Nota-se, na Tabela 3, com relação à expectativa dos clientes referente ao pronto atendimento na recepção da empresa que $5 \%$ dos clientes pesquisados não responderam essa questão, $80 \%$ tem e expectativa de ser ótimo o pronto atendimento na recepção da empresa, 12,5\% pensam ser muito bom o atendimento na recepção e 2,5\% pensam ser regular o item avaliado. Boa parte dos pesquisados possuem a expectativa de ser ótimo o pronto atendimento na recepção da empresa. Através dos dados da Tabela 4 nota-se a percepção dos clientes após o contato cliente/empresa com relação ao pronto atendimento na recepção da empresa. 
Tabela 4 - Percepção: pronto atendimento na recepção

\begin{tabular}{cc}
\hline Pronto atendimento recepção & Percentual \\
\hline Não responderam & $7,50 \%$ \\
Ótimo & $30,00 \%$ \\
Muito bom & $35,00 \%$ \\
Bom & $20,00 \%$ \\
Regular & $7,50 \%$ \\
Péssimo & $0,00 \%$ \\
Total & $100 \%$ \\
\hline
\end{tabular}

Fonte: Autoria própria (2011)

De acordo com a Tabela 4 é possível notar em relação à percepção dos pesquisados sobre o item pesquisado, que $7,5 \%$ não responderam, $30 \%$ consideram ótimo o pronto atendimento na recepção, $35 \%$ julgam ser muito bom, $20 \%$ bom e $7,5 \%$ responderam ser regular o pronto atendimento na recepção da empresa.

Pela comparação entre expectativa e percepção dos clientes quanto ao pronto atendimento na recepção da empresa, nota-se que há uma grande diferença entre o que os clientes esperavam do atendimento para com o que realmente receberam. Com isso pode-se verificar que os clientes estão insatisfeitos com o primeiro contato com a empresa. Esse ponto é de grande importância, pois é a primeira comunicação, primeiro contato com os clientes e este aspecto é muito importante para as demais etapas da prestação do serviço.

Visualiza-se na Tabela 5 os resultados em relação à expectativa dos clientes quanto à recepção e sala de espera adequada.

Tabela 5 - Expectativa: recepção e sala de espera adequada

\begin{tabular}{cc}
\hline Recepção e sala de espera adequada & Percentual \\
\hline Ótimo & $82,50 \%$ \\
Muito bom & $17,50 \%$ \\
Bom & $0,00 \%$ \\
Regular & $0,00 \%$ \\
Péssimo & $0,00 \%$ \\
Total & $100 \%$ \\
\hline
\end{tabular}

Fonte: Autoria própria (2011)

Nota-se na Tabela 5 que $82,50 \%$ dos pesquisados tinham a expectativa de serem ótimas a recepção e a sala de espera e $17,5 \%$ pensam ser muito bom. Nota-se que a maioria dos pesquisados possuem uma ótima expectativa em relação a recepção e sala de espera adequada da empresa.

Na Tabela 6, é apresentada a percepção dos pesquisados em relação à recepção e sala de espera adequada. 
Tabela 6 - Percepção: recepção e sala de espera adequada

\begin{tabular}{cc}
\hline Recepção/sala de espera adequadas & Percentual \\
\hline Não responderam & $2,50 \%$ \\
Ótimo & $37,50 \%$ \\
Muito bom & $40,00 \%$ \\
Bom & $17,50 \%$ \\
Regular & $2,50 \%$ \\
Péssimo & $0,00 \%$ \\
Total & $100 \%$ \\
\hline
\end{tabular}

Fonte: Autoria própria (2011)

Através da Tabela 6 verifica-se a percepção dos clientes em relação à recepção e sala de espera da empresa. Não responderam essa questão 2,5\% dos pesquisados, 37,50\% julgam ser ótimo a recepção e a sala de espera, $40 \%$ classificam como sendo muito bom, $17,50 \%$ bom e 2,50\% consideram regular a recepção e sala de espera.

Pela comparação entre a expectativa e a percepção do item recepção e sala de espera adequada é possível verificar que uma boa parcela dos entrevistados esperavam ter uma ótima sala de espera, mas que após entrar na empresa e utilizar a mesma, a maior parte respondeu ser muito bom. Através desses dados pode-se definir que a empresa pode melhorar sua sala de espera, para acomodar seus clientes enquanto aguardam algum serviço ou atendimento para manter em ótima a percepção dos clientes, assim como eram suas expectativas.

Através da Tabela 7 pode-se constatar a expectativa dos clientes com relação a funcionários bem apresentados.

Tabela 7 - Expectativa: funcionários bem apresentados

\begin{tabular}{cc}
\hline Funcionários bem apresentados & Percentual \\
\hline Ótimo & $75,00 \%$ \\
Muito bom & $22,50 \%$ \\
Bom & $2,50 \%$ \\
Regular & $0,00 \%$ \\
Péssimo & $0,00 \%$ \\
Total & $100 \%$ \\
\hline
\end{tabular}

Fonte: Autoria própria (2011)

Com relação à expectativa dos clientes quanto aos funcionários bem apresentados, a Tabela 7 revela que $75 \%$ pensam ser ótimo, $22,50 \%$ pensam ser muito bom e 2,50\% bom. A maioria dos entrevistados quanto a funcionários bem apresentados espera ser ótimo. Na Tabela 8 , observa-se a percepção dos clientes entrevistados quanto a funcionários bem apresentados.

Tabela 8 - Percepção: funcionários bem apresentados

\begin{tabular}{cc}
\hline Funcionários bem apresentados & Percentual \\
\hline Não responderam & $2,50 \%$ \\
Ótimo & $27,50 \%$ \\
Muito bom & $50,00 \%$ \\
Bom & $17,50 \%$ \\
Regular & $2,50 \%$ \\
Péssimo & $0,00 \%$ \\
Total & $100 \%$ \\
\hline
\end{tabular}

Fonte: Autoria própria (2011) 
Através da Tabela 8 observa-se que com relação à percepção dos funcionários bem apresentados, 2,50\% dos entrevistados não responderam, 27,50\% consideram ótimo, $50 \%$ muito bom, $17,50 \%$ bom e $2,50 \%$ regular.

A respeito da expectativa e percepção dos clientes quanto ao item avaliado, verifica-se que grande parte tinha expectativa de ser ótimo, mas a metade dos entrevistados responderam ser muito bom esse item avaliado. Esse resultado de percepção mais baixa que a expectativa pode ser em função de que o serviço realizado pelos mecânicos e técnicos compromete a boa apresentação e limpeza de seus uniformes.

Constam na Tabela 9 os resultados em relação à expectativa dos clientes sobre os equipamentos e ferramentas que a empresa utiliza no sentido de os mesmos serem adequados para resolução dos problemas trazidos pelos clientes.

Tabela 9 - Expectativa: equipamentos e ferramentas adequados

\begin{tabular}{cc}
\hline Equipamentos e ferramentas adequados & Percentual \\
\hline Ótimo & $70,00 \%$ \\
Muito bom & $27,50 \%$ \\
Bom & $2,50 \%$ \\
Regular & $0,00 \%$ \\
Péssimo & $0,00 \%$ \\
Total & $100 \%$ \\
\hline
\end{tabular}

Fonte: Autoria própria (2011)

Observa-se na Tabela 9 que $70 \%$ dos pesquisados tinham a expectativa de serem ótimos os equipamentos e ferramentas da empresa. Outros $27,50 \%$ pensam ser muito bom o item avaliado e 2,5\% acham bom. Nota-se que a maioria dos pesquisados possuem uma ótima expectativa em relação aos equipamentos e às ferramentas da empresa.

A Tabela 10 refere-se à percepção dos pesquisados em relação aos equipamentos e às ferramentas da empresa.

Tabela 10 - Percepção: equipamentos/ ferramentas adequados

\begin{tabular}{cc}
\hline Equipamentos/ferramentas adequados & Percentual \\
\hline Não responderam & $5,00 \%$ \\
Ótimo & $20,00 \%$ \\
Muito bom & $40,00 \%$ \\
Bom & $27,50 \%$ \\
Regular & $7,50 \%$ \\
Péssimo & $0,00 \%$ \\
Total & $100 \%$ \\
\hline
\end{tabular}

Fonte: Autoria própria (2011)

De acordo com a Tabela 10 é possível notar em relação à percepção dos pesquisados sobre o item pesquisado, que $5 \%$ não responderam, $20 \%$ consideram ótimos os equipamentos/ferramentas da empresa. Outros $40 \%$ consideram muito boa a avaliação do item, $27,5 \%$ pensam ser bons os equipamentos/ferramentas e apenas $7,5 \%$ consideram regular. 
Pela comparação entre a expectativa e a percepção do item ferramentas/equipamentos adequados, observa-se uma discrepância em relação aos resultados. A maioria dos pesquisados tinha alta expectativa sobre o item, o que acabou não se confirmando após o contato com a empresa. Seria importante que a empresa tivesse uma atenção especial em relação a este fator, providenciando melhorias e novos equipamentos/ferramentas. Investir em novos equipamentos, em novas tecnologias ajudaria e acrescentaria para a empresa na prestação de seus serviços.

Com relação ao item disponibilidade de peças, $72,50 \%$ dos clientes pesquisados tinham a expectativa de que fosse ótimo, $25 \%$ muito bom e 2,50\% bom. A maioria dos pesquisados pensam que o estoque da empresa abrange todos os tipos de peças, o que leva o cliente a acreditar em rápida resolução dos problemas e consertos. Mas, considerando a percepção desse item avaliado, 7,50\% dos entrevistados não responderam essa questão, outros 35\% julgam ser ótimo, 47,50\% muito bom, 7,50\% bom e 2,50\% regular. Com base na expectativa e percepção dos clientes da empresa em relação à disponibilidade de peças, observa-se que existe uma alta expectativa em relação ao estoque da empresa, havendo uma certa diferença com o que realmente os clientes presenciam. Um pouco menos da metade dos entrevistados julgam ser muito bom, isso se deve em função de demora na entrega ou encomenda de alguma peça. A empresa precisa cuidar esse ponto, pois a ótima assistência e atendimento pós- venda é algo que ela preza bastante.

Quanto aos resultados em relação à expectativa dos clientes sobre a efetiva resolução dos problemas, $90 \%$ dos entrevistados esperam que seja ótimo e outros $10 \%$ muito boa a expectativa relacionada à efetividade na resolução do problema apresentado. Isso significa que os clientes da empresa confiam no serviço e na assistência que é prestada aos maquinários. Em relação à percepção da efetiva resolução dos problemas, nota-se que $80 \%$ dos clientes pesquisados consideram ótimo e apenas $20 \%$ muito bom. Sendo assim, observa-se que não existe grande diferença com relação à expectativa e à percepção, ou seja, os clientes confiam e a maioria está satisfeita com os consertos e efetiva resolução dos problemas.

Nota-se que, com relação à expectativa dos clientes frente a entrega do produto/serviço no prazo combinado, que a mesma é bem alta, 87,50\% pensam ser ótimo e outros 12,50\% muito bom. Quanto à percepção desse item avaliado, 2,50\% dos pesquisados não responderam, 35\% julgam ser ótimo, outros $45 \%$ muito bom e 17,50\% bom. Com isso, observa-se que existe uma considerável diferença entre a expectativa e a percepção desse item avaliado. A empresa precisa melhorar e buscar formas para que não ocorram atrasos nas entregas, além de comunicar ao cliente, caso seja necessário, um prazo maior para resolução do problema.

Observa-se, quanto aos resultados da expectativa dos clientes em relação ao domínio/conhecimento específico sobre os problemas do maquinário, que $90 \%$ esperam ser ótimo e $10 \%$ muito bom o conhecimento dos colaboradores sobre os problemas que os maquinários podem 
apresentar. Quanto à percepção desse item avaliado, nota-se que 2,50\% não responderam, 55\% julgam ser ótimo e $45 \%$ muito bom. Com esses resultados percebe-se que os funcionários da empresa estão bem preparados e treinados para solucionar os problemas. Existe uma certa diferença entre a expectativa e a percepção do serviço prestado, mas nenhum cliente acusou ser péssimo ou regular, o que torna a prestação de serviço bem vista pelos clientes e demonstra domínio e conhecimento específicos dos maquinários comercializados pela empresa.

Tendo em vista a expectativa dos clientes quanto à honestidade e sinceridade nos serviços prestados pela empresa, observa-se que $88 \%$ esperam ser ótimo e $12 \%$ muito bom. Quanto a percepção, nota-se que em relação à honestidade e sinceridade, 52\% dos clientes pesquisados julgam ser ótimo e outros $45 \%$ julgam ser muito bom, sendo que $2,50 \%$ não responderam essa questão. Com isso, observa-se que existe transparência nas negociações, e que são realizados apenas serviços necessários e que o cliente tem conhecimento de tudo que deve ser realizado no maquinário.

Quanto à expectativa na agilidade para o preenchimento da ordem de serviço, nota-se que $87,50 \%$ dos clientes pesquisados pensam ser ótimo e 12,50\% pensam ser muito bom. Já a percepção que estes clientes têm quanto a agilidade para o preenchimento da ordem de serviço, observa-se que 47,50\% julgam ser ótimo, 32,50\% muito bom, outros $17,50 \%$ bom e 2,50\% não responderam. Com esses resultados pode-se observar grande diferença entre o que o cliente espera e o que realmente ocorre no momento de preenchimento da ordem de serviço. O preenchimento da ordem de serviço é algo simples para empresa e funcionários, mas que fornecido de forma mais rápida pode elevar o grau de satisfação do cliente, evitando perda de tempo e espera sem necessidade.

Visualiza-se na Tabela 11 à expectativa dos clientes sobre a atenção personalizada aos mesmos.

Tabela 11 - Expectativa: atenção personalizada

\begin{tabular}{cc}
\hline Atenção personalizada ao cliente & Percentual \\
\hline Ótimo & $90,00 \%$ \\
Muito bom & $10,00 \%$ \\
Bom & $0,00 \%$ \\
Regular & $0,00 \%$ \\
Péssimo & $0,00 \%$ \\
Total & $100 \%$ \\
\hline
\end{tabular}

Fonte: Autoria própria (2011)

Observa-se, na Tabela 11, que 90\% dos pesquisados tinham a expectativa de ser ótima a atenção personalizada ao cliente da empresa. Outros $10 \%$ pensam ser muito bom o item avaliado. Nota-se que a maioria dos pesquisados possuem uma ótima expectativa em relação à atenção personalizada.

A Tabela 12 apresenta a percepção dos pesquisados em relação a esse atendimento personalizado da empresa. 
Tabela 12 - Percepção: atenção personalizada ao cliente

\begin{tabular}{cc}
\hline Atenção personalizada ao cliente & Percentual \\
\hline Não responderam & $2,50 \%$ \\
Ótimo & $37,50 \%$ \\
Muito bom & $45,00 \%$ \\
Bom & $15,00 \%$ \\
Regular & $0,00 \%$ \\
Péssimo & $0,00 \%$ \\
Total & $100 \%$ \\
\hline
\end{tabular}

Fonte: Autoria própria (2011)

Conforme a Tabela 12 é possível notar, em relação a atenção personalizada aos clientes, que $37,5 \%$ consideram ótima a atenção personalizada da empresa. Outros $45 \%$ consideram muito boa a avaliação do item, 15\% pensam ser boas, e apenas 2,5\% dos clientes pesquisados não responderam.

Pela comparação entre a expectativa e a percepção do item atenção personalizada aos clientes, observa-se uma discrepância em relação aos resultados. A maioria dos pesquisados tinha alta expectativa sobre o item, o que acabou não se confirmando após o contato com a empresa. Seria importante que a empresa tivesse uma atenção especial em relação a este fator, criando um maior vínculo com o cliente, personalizando o atendimento e fazendo com que seus clientes se sintam especiais para empresa.

Através da Tabela 13 pode-se notar a expectativa dos clientes com relação à agilidade (rapidez) na prestação do serviço.

Tabela 13 - Expectativa: agilidade na prestação do serviço

\begin{tabular}{cc}
\hline Agilidade na prestação do serviço & Percentual \\
\hline Ótimo & $90,00 \%$ \\
Muito bom & $10,00 \%$ \\
Bom & $0,00 \%$ \\
Regular & $0,00 \%$ \\
Péssimo & $0,00 \%$ \\
Total & $100 \%$ \\
\hline
\end{tabular}

Fonte: Autoria própria (2011)

Os dados da Tabela 13 evidenciam alta expectativa dos clientes em relação à agilidade (rapidez) no serviço prestado pela empresa. A maioria dos entrevistados responderam ótimo, tendo grandes expectativas com relação a esse item avaliado, apenas $10 \%$ dos entrevistados esperam ser muito bom a agilidade nos serviços oferecidos pela empresa.

A Tabela 14 refere-se à percepção dos pesquisados em relação a agilidade na prestação do serviço. 
Tabela 14 - Percepção: agilidade na prestação do serviço

\begin{tabular}{cc}
\hline Agilidade na prestação do serviço & Percentual \\
\hline Ótimo & $82,50 \%$ \\
Muito bom & $15,00 \%$ \\
Bom & $2,50 \%$ \\
Regular & $0,00 \%$ \\
Péssimo & $0,00 \%$ \\
Total & $100 \%$ \\
\hline
\end{tabular}

Fonte: Autoria própria (2011)

A Tabela 14 revela a percepção do cliente com relação à agilidade na prestação do serviço. Nota-se que $82,50 \%$ dos pesquisado julgam ser ótimo. Outros $15 \%$ consideram muito bom e 2,50\% bom. Observa-se que grande parte dos clientes confiam e sabem que o serviço será realizado de forma rápida, ágil, e com eficiência, ou seja, seus problemas serão solucionados em um curto prazo.

Outro item avaliado levou em consideração a disponibilidade de peças, ferramentas e mão de obra especializada para a prestação do serviço. De certa forma, pela utilização diária dos maquinários, os clientes necessitam de rapidez e resolução dos problemas. Através do item avaliado, observa-se que as expectativas dos clientes foram alcançadas, mas que a empresa ainda pode melhorar para proporcionar satisfação a todos os clientes.

\section{Considerações finais}

Em meio às constantes mudanças no ambiente empresarial, a concorrência acirrada, forte globalização, desenvolvimento de tecnologias, é muito importante que as empresas consigam avaliar e detectar o que os seus clientes estão buscando. Por isso, pesquisas que avaliam e comparam a expectativa e a percepção dos produtos/serviços que a empresa oferece proporcionam um grande diferencial, pois, mostra se as estratégias utilizadas pela empresa para atingir a satisfação de seus clientes estão causando efeito positivo.

Com a realização deste estudo, constatou-se que os principais serviços prestados pela empresa são serviços de mecânica em colheitadeiras, tratores e plantadeiras. A empresa oferece assistência técnica especializada em uma determinada marca de maquinários agrícolas, através de profissionais capacitados para dar total suporte no pós-vendas. Revisões, manutenções, consertos, trocas de peças, troca de óleo, manutenção na pintura dos tratores, limpeza profunda são também serviços que a empresa oferece a seus clientes.

Concluiu-se que, na maioria das variáveis analisadas, utilizando o modelo da escala SERVQUAL, a expectativa dos clientes excedeu a percepção dos serviços prestados, o que reflete que a empresa deve tomar algumas ações corretivas para reduzir esses gaps ou discrepâncias encontradas. É notável que os clientes da empresa tenham total confiança nos serviços prestados pela mesma, mas são os detalhes que fazem a diferença para um atendimento personalizado ao cliente, tais como melhorias no ambiente interno da empresa, conforto na sala de espera, melhor 
comunicação dos funcionários com os clientes, esclarecimento de dúvidas e valores, disponibilidade de tempo para atender e tirar dúvidas são alguns fatores que a empresa deve estar atenta para conseguir corrigir essas pequenas falhas, mas que para o cliente faz diferença.

Em relação às limitações do estudo, destaca-se a questão da aplicação dos questionários, devido ao perfil dos clientes da empresa, ou seja, por serem na maioria dos casos produtores rurais, salienta-se que os mesmos não costumam destinar tempo para realização desse tipo de atividade.

Ao concluir o presente estudo, acredita-se que novos possam ser realizados, visando contribuir ainda mais ao tema. Nesse sentido, sugere-se como futuras pesquisas, além de replicar esta em empresas de outros segmentos da economia a fim de verificar as percepções dos clientes em relação aos serviços em organizações de diferentes setores, também acredita-se que este trabalho possa ser aplicado nas filiais da própria empresa aqui estudada, com o próposito de confrontar os resultados obtidos em relação às outras, o que pode ser melhorado visando um padrão no atendimento.

\begin{abstract}
Amid the ever-changing business environment, fierce competition and the development of new technologies, it is important that companies unable to assess whether their products and / or services are meeting customer expectations. And by applying the scale Servqual is possible to evaluate these main differences or discrepancies between the expectation that the client had in relation to the service with their perceptions after the service offered. In this context, this study aims to conduct an evaluation of the services provided by a trading company of agricultural machinery in order to add value to their processes and work operations. As for the methodological procedures, the research is characterized as qualitative and quantitative, descriptive, being carried out using the tool Servqual by applying a questionnaire to a sample of 40 clients of the company under study. The results show that the majority of variables analyzed, exceeded the expectations of the customers' perception of services, reflecting that the company needs to take some corrective actions to reduce these gaps and found, from the knowledge of these differences have been conditions and work to improve upon the operations or processes that need to be improved.
\end{abstract}

Key-words: quality; services; customers.

\title{
Referências
}

AL TAMIMI, H.; JABNOUN, N. Financial performance and service quality in UAE banks. Finance India, v. 20, n. 1, 2006.

ANTUNES, E. M.; SIMÕES, F. A. Utilização da psicometria para avaliar a qualidade do serviço de transporte: um estudo de caso. Revista Gestão Industrial, Ponta Grossa, v. 09, n. 02, p. 416-439, 2013.

cross ref

CAMARERO, C. Relationship orientation or service quality? What is the trigger of performance in financial and insurance services? The International Journal of Bank Marketing, v. 25, n. 6, 2007.

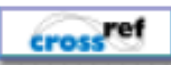


CARVALHO, G. J. de; CAMPOS, R. de. Análise dos benefícios do EDI para a competitividade logística das organizações. Revista Gestão Industrial, Ponta Grossa, v. 08, n. 04, p. 105-120, 2012.

cross ref

CHAKER, M. N.; JABNOUN, N. Barriers to service quality in Islamic banks in Qata. International Journal of Commerce and Management, v. 20, n. 4, p. 296-307, 2010.

cross ref

FACHIN, O. Fundamentos de metodologia. 3. ed. São Paulo: Saraiva, 2001.

FITZSIMMONS, J.; FITZSIMMONS, M. Administração de serviços: operações, estratégia e tecnologia de informação. 2. ed. Porto Alegre: Bookman, 2010.

FRAZIER, G. Administração da produção e operações. 8. ed. São Paulo: PioneiraThomsom Learning, 2001.

GIANESI, I. CORRÊA, H. Administração estratégica de serviços: operações para satisfação do cliente. São Paulo: Atlas, 1996.

GIL, A. C. Como elaborar projetos de pesquisa. 5. ed. São Paulo: Atlas, 2010.

GONSALVES, E. P. Conversas sobre iniciação à pesquisa científica. 4. ed. São Paulo: Alínea, 2007.

GUARIENTI, A. et al. Avaliação da qualidade percebida em serviços através da escala SERVQUAL. In: ENCONTRO NACIONAL DE ENGENHARIA DE PRODUÇÃO, 26, 2006, Fortaleza. Anais... Fortaleza: ABEPRO, 2006.

Disponível em: <http://www.abepro.org.br/biblioteca/ENEGEP2006_TR470326_7203.pdf >. Acesso em: 24 nov. 2011.

HUME, M. Understanding core and peripheral service quality in customer repurchase of the performing arts. Managing Service Quality, v. 18, n. 4, 2008.

cross ref

LAS CASAS, A. L. Administração de marketing: conceitos, planejamento e aplicações a realidade brasileira. São Paulo: Atlas, 2006.

MALHOTRA, M. Administração da produção e operações. São Paulo: Pearson Prentice Hall, 2008.

MALHOTRA, N. Pesquisa de marketing: uma orientação aplicada. 3. ed. Porto Alegre: Bookman, 2001.

MARTINS, P.; LAUGENI, F. Administração da produção. São Paulo: Saraiva, 2005.

MARTINS, R. B. Metodologia científica: como tornar mais agradável a elaboração de trabalhos acadêmicos. Curitiba: Juruá, 2010.

MOREIRA, D. A. Administração da produção e operações. 2. ed. São Paulo: Cengage, 2008.

OLIVEIRA, E. A. de; LEAL, G. C. L.; FENERICH, F. C. Análise da qualidade dos serviços em uma escola pública utilizando a ferramenta SERVPERF. Revista Gestão Industrial, Ponta Grossa, v. 09, n. 01, p. 165-179, 2013.

cross ref

PRASS, R. M.; SANT'ANNA, L. C.; GODOY, L. P. Avaliação da qualidade de serviços prestados na área educacional através do modelo SERVQUAL. Revista Gestão Industrial, Ponta Grossa, v. 06, n. 02, p. 213-231, 2010.

\section{cross ref}

RUSSOMANO, V. H. Planejamento e controle da produção. 6. ed. São Paulo: Pioneira, 2000.

SCHMENNER, R. Administração de operações em serviços. São Paulo: Futura, 1999.

SILVA, L. C. S.; KOVALESKI, J. L.; GAIA, S. Qualidade em serviços: uma análise teórica sobre as principais características. Revista Gestão Industrial, Ponta Grossa, v. 07, n. 04, p. 140-153, 2011. 
SLACK, N. et al. Administração da produção. São Paulo: Atlas, 1999.

SOLVANG, B. K. Satisfaction, loyalty, and repurchase: a study of Norwegian customers of furniture and grocery stores. Journal of Consumer Satisfaction, Dissatisfaction and Complaining Behavior, v. 20, p. 110-22, 2007.

SPRENG, R. A.; MACKENGENZIE, S. B.; OLSHAVASKY, R.W. A re-examination of the determinants of consumer satisfaction. Journal of Marketing, v. 60, p. 15-32, 1996.

\section{cross ref}

TUBINO, D. Planejamento e controle da produção: teoria e prática. São Paulo: Atlas, 2007.

VEIGA, C. Modelo empírico para a seleção de máquinas agrícolas na cultura da soja considerando a pontualidade na semeadura. 2000. 75 f. Dissertação (Mestrado em Máquinas Agrícolas) - Escola Superior de Agricultura Luiz de Queiroz, Universidade de São Paulo, Piracicaba, 2000.

ZEITHAML, V.; BITNER. M.; GREMLER, D. Marketing de serviços: a empresa com foco no cliente. 5. ed. Porto Alegre: Bookman: 2001.

\section{Dados dos autores:}

\section{Nome completo: Andressa Pisoni}

Filiação institucional: Centro Universitário Franciscano - UNIFRA

Departamento: Curso de Administração

Endereço completo para correspondência: Rua Silva Jardim, nº 1175. Centro. Santa Maria - RS;

Conjunto III - Prédio 13 - Sala 118; CEP: 97010-491.

Telefone para contato: (55) 9637-7186

e-mail: andressa.pisoni@hotmail.com

\section{Nome completo: Juliana Andreia Rüdell Boligon}

Filiação institucional: Centro Universitário Franciscano - UNIFRA

Função ou cargo ocupado: Professora do Curso de Administração

Endereço completo para correspondência: Rua/Travessa: Dom Ático Eusébio da Rocha; $n^{\text {o: }}$ 255;

Bairro: Dom Antônio Reis; Cidade: Santa Maria - RS; CEP: 97065- 080.

Telefone para contato: (55) 9947-8333

e-mail: julianaboligon@unifra.br

Nome completo: Flaviani Souto Bolzan Medeiros

Filiação institucional: Universidade Federal de Santa Maria - UFSM

Função ou cargo ocupado: Mestranda em Engenharia de Produção; Bolsista do CNPq

Endereço completo para correspondência: Rua Fermino Nicoloso; Quadra 23; Casa: 14; Bairro:

Tancredo Neves; Cidade: Santa Maria - RS; CEP: 97032-460 
Telefone para contato: (55) 9604-5878

e-mail: flaviani.13@gmail.com

Nome Completo: Élio Sérgio Denardin

Filiação institucional: Centro Universitário Franciscano - UNIFRA

Função ou cargo ocupado: Professor do Curso de Administração

Endereço completo para correspondência: Rua General Neto, no: 732; Bairro: Centro; Santa Maria RS; CEP: 97050- 240.

Telefones para contato: (55) 3026-2530

e-mail: eliodenardin@hotmail.com

Nome completo: Lisandra Taschetto Murini

Filiação institucional: Centro Universitário Franciscano - UNIFRA

Função ou cargo ocupado: Professora do Curso de Administração

Endereço completo para correspondência: Rua: Silva Jardim, nº 1175. Centro. Santa Maria - RS;

Conjunto III - Prédio 13 - Sala 118; CEP: 97010-491.

Telefones para contato: (55) 9948-5626

e-mail: lisandra@unifra.br

Submetido em: 21/05/2012

Aceito em: 05/08/2013 